\title{
Identification of candidate structured RNAs in the marine organism 'Candidatus Pelagibacter ubique'
}

\author{
Michelle M Meyer ${ }^{1}$, Tyler D Ames ${ }^{1}$, Daniel P Smith ${ }^{4}$, Zasha Weinberg 3 , \\ Michael S Schwalbach ${ }^{4}$, Stephen J Giovannoni ${ }^{4}$ and Ronald R Breaker*1,2,3
}

\author{
Address: ${ }^{1}$ Department of Molecular Cellular and Developmental Biology, Yale University, Box 208103, New Haven, CT 06520, USA, ${ }^{2}$ Department \\ of Molecular Biophysics and Biochemistry, Yale University, Box 208103, New Haven, CT 06520, USA, ${ }^{3}$ Howard Hughes Medical Institute, Yale \\ University, Box 208103, New Haven, CT 06520, USA and " Department of Microbiology, Oregon State University, Corvallis, OR 97333, USA \\ Email: Michelle M Meyer - michelle.meyer@yale.edu; Tyler D Ames - tyler.ames@yale.edu; Daniel P Smith - dansmith@orst.edu; \\ Zasha Weinberg - zasha.weinberg@yale.edu; Michael S Schwalbach - schwalbm@onid.orst.edu; \\ Stephen J Giovannoni - steve.giovannoni@oregonstate.edu; Ronald R Breaker* - ronald.breaker@yale.edu \\ * Corresponding author
}

Published: 16 June 2009

BMC Genomics 2009, 10:268 doi:10.1186/147|-2164-10-268
Received: 6 January 2009

Accepted: 16 June 2009

This article is available from: http://www.biomedcentral.com/I47/-2/64/I0/268

(c) 2009 Meyer et al; licensee BioMed Central Ltd.

This is an Open Access article distributed under the terms of the Creative Commons Attribution License (http://creativecommons.org/licenses/by/2.0), which permits unrestricted use, distribution, and reproduction in any medium, provided the original work is properly cited.

\begin{abstract}
Background: Metagenomic sequence data are proving to be a vast resource for the discovery of biological components. Yet analysis of this data to identify functional RNAs lags behind efforts to characterize protein diversity. The genome of 'Candidatus Pelagibacter ubique' HTCC 1062 is the closest match for approximately $20 \%$ of marine metagenomic sequence reads. It is also small, contains little non-coding DNA, and has strikingly low GC content.

Results: To aid the discovery of RNA motifs within the marine metagenome we exploited the genomic properties of 'Cand. P. ubique' by targeting our search to long intergenic regions (IGRs) with relatively high GC content. Analysis of known RNAs (rRNA, tRNA, riboswitches etc.) shows that structured RNAs are significantly enriched in such IGRs. To identify additional candidate structured RNAs, we examined other IGRs with similar characteristics from 'Cand. P. ubique' using comparative genomics approaches in conjunction with marine metagenomic data. Employing this strategy, we discovered four candidate structured RNAs including a new riboswitch class as well as three additional likely cis-regulatory elements that precede genes encoding ribosomal proteins S2 and SI2, and the cytoplasmic protein component of the signal recognition particle. We also describe four additional potential RNA motifs with few or no examples occurring outside the metagenomic data.
\end{abstract}

Conclusion: This work begins the process of identifying functional RNA motifs present in the metagenomic data and illustrates how existing completed genomes may be used to aid in this task.

\section{Background}

The discovery of many RNA sequences that do not encode proteins (non-coding RNAs or ncRNA) and have biological functions beyond those of tRNA and rRNA, has significantly expanded the known role of RNA in diverse cellular processes. Consequently, there is a growing effort to systematically identify ncRNAs utilizing both experimental and computational techniques. Experimental approaches are typically used to identify non-coding portions of an organism's genome that are actively being tran- 
scribed. These approaches are not dependent on the identification of conserved RNA sequences or secondary structures, and therefore are well-suited for the discovery of unstructured or poorly-conserved ncRNAs. However, experimental limitations can cause some RNAs to be missed, and the false-positive rate may be high due to "transcriptional noise" [1,2]. Alternatively, computational methods seek to identify evidence of conserved RNA sequences and secondary structures through comparative genomics $[3,4]$. However, such methods usually cannot be used to identify RNA motifs that may not have conserved secondary structure, are small with few basepairing elements, or are not well-represented in genomic sequence databases.

Marine metagenomic sequence data are a proven resource for the discovery of novel protein diversity and have provided additional examples for thousands of previously identified open reading frames (ORFs) with no known homologs [5]. While there have been surveys conducted with the marine metagenome to discover additional examples of known ncRNAs [6,7], there have been no studies explicitly examining these data for novel RNA motifs, in part due to unique computational challenges inherent to metagenomic datasets. Specifically, the exceedingly large amount of sequence data available $(\sim 7$ billion base pairs), relatively poor annotation of protein coding regions due to a high frequency of fragmentary genes that result from short sequence reads, and comparatively high sequencing error rates make metagenomic data analysis difficult [8-10].

To circumvent many of the challenges associated with analyzing metagenomic sequence data, we have used the genome of 'Cand. P. ubique' HTCC 1062 as a starting point to discover new RNA motifs within the marine metagenome. Bacteria of the SAR11 clade, of which 'Cand. $P$. ubique' is a representative, are found throughout the world's oceans and are the dominant aerobic heterotrophs in marine surface waters [11]. Given its numeric advantage, genes from members of the SAR11 clade are well-represented in marine metagenomic libraries with nearly $20 \%$ of sequence reads from the Global Oceanographic Survey (GOS) matching most closely to genes present in the 'Cand. P. ubique' genome [12,13]. Only $\sim 30 \%$ of the GOS reads could be aligned well to the 584 available reference genomes. The other predominant genera represented in the GOS data are Prochlorococcus, Synechococcus, Burkholderia, and Shewanella, none of which are closely related to 'Cand. P. ubique'. While, alignments to every reference genome were identified, typically they showed identity to regions corresponding to large, highly conserved genes [13].
At 1.3 million base pairs, the genome of 'Cand. P. ubique' is the smallest known for a free-living organism, but it appears to encode for nearly all the basic functions of Alphaproteobacteria cells [14]. The genome contains very little non-coding DNA, with a median intergenic region (IGR) length of 3 nucleotides. In addition, the organism has remarkably low GC content (29\%). While evaluating nucleotide composition is usually not a viable method for identifying ncRNAs [15], in genomes with a strong AT bias or hyperthermophilic environment, the higher GC content necessary to maintain a stable RNA structure may be used to identify candidate ncRNAs [16-19]. 'Cand. P. ubique' offers an ideal opportunity to utilize nucleotide composition as its genome has very few long IGRs, which are generally low GC ( $23 \%$ on average).

In the current study we combine nucleotide composition with comparative genomics approaches to identify novel structured RNA motifs in 'Cand. P. ubique' and the marine metagenomic data. First, we demonstrate that longer, higher GC 'Cand. P. ubique' IGRs are much more likely to contain structured RNAs (rRNAs, tRNAs, etc.). Subsequently, we utilized the IGRs in 'Cand. P. ubique' with similar properties that lack assigned ncRNAs as the starting point for a comparative sequence analysis strategy that takes advantage of marine metagenomic sequences. We discovered four likely structured ncRNAs including a new riboswitch class, and three other candidate cis-regulatory motifs. In addition we describe several other conserved IGRs that encode potential structured RNA elements.

\section{Results \\ Analysis strategy}

To identify potential ncRNAs in the genome of 'Cand. P. ubique', all IGRs were extracted from the 'Cand. P. ubique' genome and ranked by GC content. When 'Cand. P. ubique' IGRs are plotted by their length and percent GC, those containing annotated RNAs (rRNAs, tRNAs, riboswitches, etc.) cluster toward the top right of the graph (Figure 1). This finding indicates that the vast majority of GC-enriched IGRs longer than 100 bp carry annotated ncRNAs (Additional file 1).

To identify additional structured RNAs that may not be annotated, we performed BLAST searches of the remaining IGRs against the Community Cyberinfrastructure for Advanced Marine Microbial Ecology Research and Analysis (CAMERA) database [20]. Table 1 lists GC enriched 'Cand. P. ubique' IGRs longer than $100 \mathrm{bp}$ and the number of BLAST hits identified with an E-value less than $10^{-5}$ as a measure of conservation. The average number of blast hits for IGRs containing tRNAs is 2158, with a standard deviation of 1282. However, the average number of blast hits for the 'Cand. P. ubique' IGRs containing SAMII riboswitches, which are significantly smaller than a 


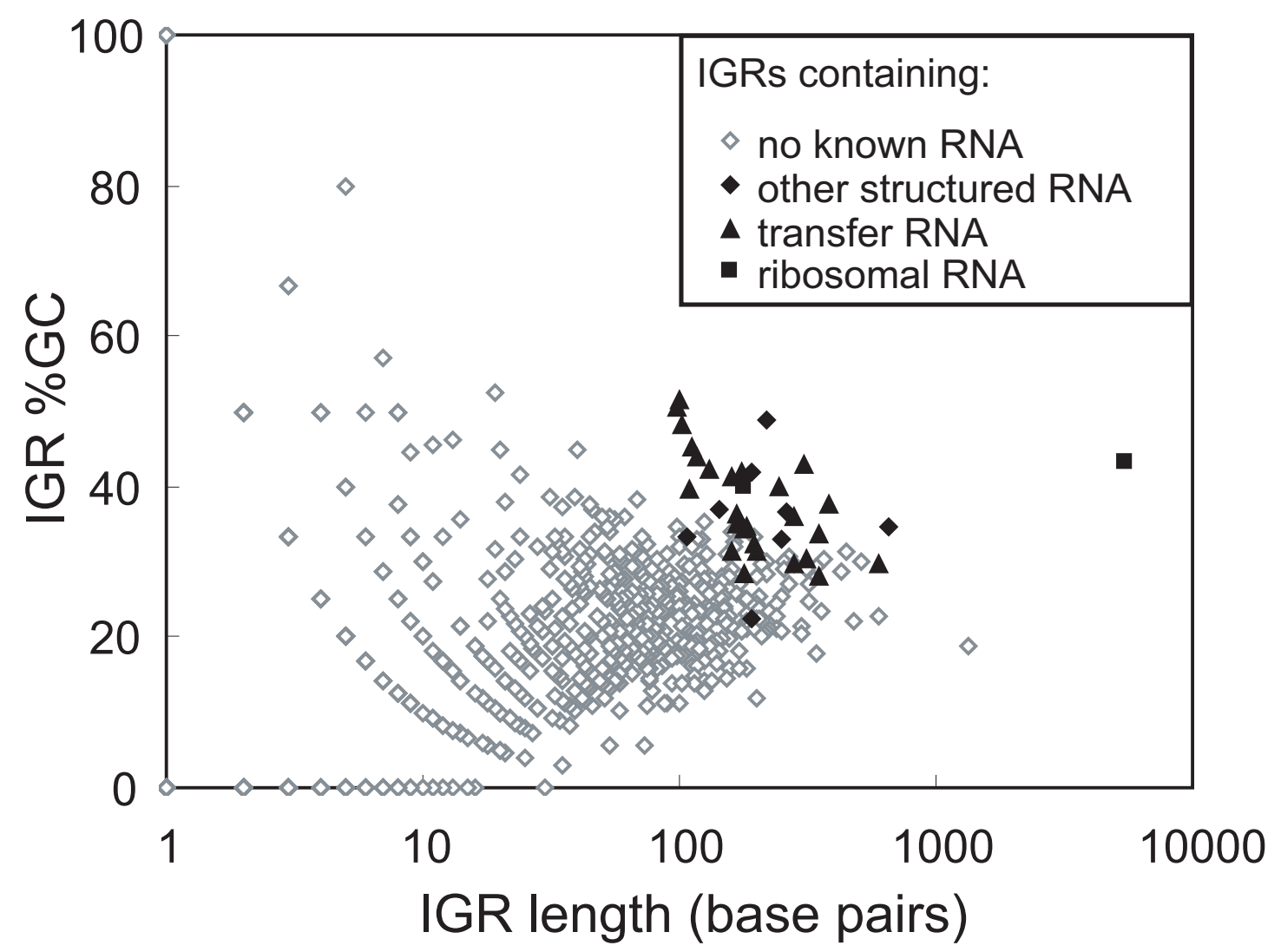

Figure I

Percent GC-content versus length of intergenic regions (IGRs) in 'Cand. P. ubique'. Transfer and ribosomal RNAs are as annotated by Rfam [24] and RefSeq (RefSeq accession NC_007205.I). Other structured RNAs include known riboswitches, 4.5S RNA (SRP RNA), RNase P RNA and tmRNA.

tRNA and most commonly present in Alpha-, Beta- and Gammaproteobacteria, is approximately 500. Based on this analysis and the need for a relatively large number of BLAST hits for subsequent comparative sequence analysis algorithms, IGRs with greater than 200 BLAST hits were further screened for unannotated ncRNAs and misannotated protein coding sequence. This screening process revealed several misannotated protein coding sequences in addition to several known structured RNAs not previously annotated (Additional file 2 - Table 1). The RNA motifs identified are typically very highly ranked on our list, and include tmRNA, the RNA component of the signal recognition particle (SRP), the RNase P RNA (class A), and a number of riboswitches (Table 1).

Identification of SRP RNA (4.5S RNA) [21] and RNase P RNA $[22,23]$ was very straightforward. Both are completely contained within their respective IGRs and conform to well-established consensus sequences [24]. We also easily identified a variety of RNA cis-regulatory ele- ments known as riboswitches [25] including two representatives of the glycine riboswitch class [26] previously described in 'Cand. P. ubique' [27], two class II SAM riboswitches (SAM-II) [28] and a TPP riboswitch [29,30].

In contrast, identification of the tmRNA [31] representative was somewhat more challenging. The tmRNA eluded identification during initial screens for several reasons. First, in the genome of 'Cand. P. ubique' the flanking gene (thyX, SAR11_0010) is likely misannotated resulting in a partial overlap of the annotated coding region with the tmRNA. While coding sequences in 'Cand. P. ubique' often overlap by several nucleotides, an in-frame methionine at position 30 of the existing annotation for thymidylate synthase sequence is most likely the correct start site based on BLAST analysis of ThyX protein sequences. Second, the genomic sequence of the tmRNA is split and permuted relative to the mature form of the RNA in 'Cand. P. ubique'. While this feature is shared by most other Alphaproteobacteria and by some Cyanobacteria [32], it 
Table I: 'Cand. P. ubique' IGRs longer than 100 bp ranked by GC content. IGRs containing tRNA and rRNA removed

\begin{tabular}{|c|c|c|c|c|c|c|c|c|}
\hline Coordinates & Length & $\% G C$ & BLAST Hits & RNA (strand) & Locus Tag & $\begin{array}{l}\text { Flanking Gene } \\
\text { Name (Strand) }\end{array}$ & Locus Tag & $\begin{array}{l}\text { Flanking Gene } \\
\text { Name (strand) }\end{array}$ \\
\hline $10302-10518$ & 217 & 48.85 & $|76|$ & tmRNA (+) & SARII_00I0 & thyX (-) & SARII_00II & COG4696 (-) \\
\hline $649763-649953$ & 191 & 41.88 & 1990 & $\begin{array}{l}\text { glycine } \\
\text { riboswitch (+) }\end{array}$ & SARII_0664 & membrane prot. $(+)$ & SARII_0666 & $\operatorname{gcv} \top(+)$ \\
\hline $493521-493664$ & 144 & 36.81 & 888 & $\begin{array}{c}4.5 \text { S RNA } \\
\text { (SRP RNA) }(+)\end{array}$ & SARII_506 & pheA (+) & SARII_0507 & $\operatorname{dnaX}(+)$ \\
\hline I I27293-I I 27553 & 261 & 36.78 & 127 & $\begin{array}{l}\text { SAM-II/SAM-V } \\
\text { riboswitch (-) }\end{array}$ & SARII_II29 & bhmt (-) & SARII_I730 & hyp. protein (-) \\
\hline $564786-564910$ & 125 & 35.2 & 611 & pntA element $(+)$ & SARII_0573 & $r p m J(+)$ & SARII_0574 & pntA (+) \\
\hline 38796-39447 & 652 & 34.51 & 2475 & $\begin{array}{l}\text { RNase P } \\
\text { RNA (-) }\end{array}$ & SARII_0033 & mraZ (-) & SARII_0034 & ybjR (-) \\
\hline $260190-260348$ & 159 & 33.96 & 1615 & ffh motif (-) & SARII_2356 & $f f h(-)$ & SARII_0257 & $\operatorname{dapF}(+)$ \\
\hline $626974-627168$ & 195 & 33.33 & 1168 & & SARII_064I & $\operatorname{rec} A(+)$ & SARII_0642 & protease (-) \\
\hline $786467-786574$ & 108 & 33.33 & 927 & $\begin{array}{c}\text { TPP } \\
\text { riboswitch (+) }\end{array}$ & SARII_08I0 & hyp. protein $(+)$ & SARII_08II & transporter $(+)$ \\
\hline $585015-585135$ & $12 \mid$ & 33.06 & $4 I$ & & SARII_0599 & COGI729 (+) & SARII_0600 & mesj $(+)$ \\
\hline $498458-498706$ & 249 & 32.93 & 2398 & $\begin{array}{l}\text { glycine } \\
\text { riboswitch (-) }\end{array}$ & SARII_05I0 & $g / c B(-)$ & SARII_05II & $\operatorname{acc} A(+)$ \\
\hline $622388-622552$ & 165 & 32.73 & $130 \mid$ & $\begin{array}{l}\text { SARII_0636 } \\
\text { element }(+)\end{array}$ & SARII_0635 & hyp. protein (-) & SARII_0636 & hyp protein $(+)$ \\
\hline | |42870-||4303| & 162 & 32.1 & 29 & & SARII_II90 & COG0659 (-) & SARII_II9I & HIT protein (-) \\
\hline $159067-159166$ & 100 & 32 & 25 & & SARII_0I56 & hyp. protein (-) & SARII_0I57 & ispA (-) \\
\hline $1292813-1292925$ & 113 & 31.86 & 57 & & SARII_I357 & livF2 (-) & SARII_I358 & $\operatorname{livG2}(-)$ \\
\hline II204I2-II20856 & 445 & 31.46 & 66 & & SARII_II64 & lipoprotein (-) & SARII_II65 & exonuclease $(+)$ \\
\hline $873155-873283$ & 129 & 31.01 & 832 & $r p s B$ motif $(+)$ & SARII_0906 & dnaE $(+)$ & SARII_0907 & $\operatorname{rps} B(+)$ \\
\hline $628285-628539$ & 255 & 30.2 & 571 & & SARII_0642 & protease (-) & SARII_0643 & alas (+) \\
\hline $1005679-1005890$ & 212 & 30.19 & 483 & SAM-V (+) & SARII_I029 & rplM (-) & SARII_I030 & $\operatorname{met} Y(+)$ \\
\hline $36|353-36| 57 \mid$ & 219 & 30.14 & 76 & & SARII_0369 & $\operatorname{grp} E(-)$ & SARII_0370 & $\begin{array}{l}\text { HAMI-like } \\
\text { prot. }(+)\end{array}$ \\
\hline I I25490-I I 25606 & 117 & 29.91 & II & & SARII_II7I & ordL (-) & SARII_II72 & osmC (-) \\
\hline I |89853-| I89956 & 104 & 29.81 & 25 & & SARII_I248 & hyp. protein (+) & SARII_I249 & hyp. protein (+) \\
\hline $676100-676308$ & 208 & 28.7 & 193 & & SARII_069I & hyp. protein (-) & SARII_0692 & yajQ (-) \\
\hline $1212757-1212865$ & 109 & 29.36 & 22 & & SARII_I279 & membrane prot. (-) & SARII_I280 & hyp. protein (+) \\
\hline 732778-732938 & 161 & 29.19 & 446 & SAM-V (-) & SARII_0750 & mmuM (-) & SARII_075I & hyp. protein. (-) \\
\hline 57720-58035 & 316 & 29.11 & 25 & & SARII_0046 & autotransporter (-) & SARII_0047 & $\begin{array}{l}\text { transcription } \\
\text { regulator }(+)\end{array}$ \\
\hline $120095-120215$ & 121 & 28.93 & 211 & $\begin{array}{c}\text { bablM } \\
\text { element }(+)\end{array}$ & SARII_0I08 & $r n h B(+)$ & SARII_0I09 & bablM (+) \\
\hline $762114-762332$ & 219 & 28.31 & 55 & & SARII_0784 & hyp. protein (+) & SARII_0785 & hyp. protein (+) \\
\hline $834435-834636$ & 202 & 28.22 & 42 & & SARII_0864 & hyp. protein (+) & SARII_0865 & transporter $(+)$ \\
\hline II64239-I I64384 & 146 & 28.08 & 0 & & SARII_I216 & ecpD $(+)$ & SARII_I2I8 & $\operatorname{sig} B(+)$ \\
\hline $52729-52884$ & 157 & 28.02 & 22 & & SARII_0042 & autotransporter (-) & SARII_0043 & hyp. protein (-) \\
\hline $1297623-1297755$ & 133 & 27.82 & 480 & rhtB element (-) & SARII_I362 & $\operatorname{rhtB}(-)$ & SARII_I363 & hyp. protein (+) \\
\hline $67504 I-675166$ & 126 & 27.78 & 205 & & SARII_0690 & hyp. protein (-) & SARII_069I & hyp. protein (-) \\
\hline $762678-763012$ & 335 & 27.76 & 76 & & SARII_0785 & hyp. protein (+) & SARII_0786 & qacH (-) \\
\hline 43688-43789 & 102 & 27.4 & 570 & & SARII_0037 & $r p o D(-)$ & SARII_0038 & dnaG (-) \\
\hline 79|867-792012 & 146 & 27.4 & 125 & & SARII_08I7 & hupA (+) & SARII_08I8 & $a m t B(+)$ \\
\hline II328|2-I I32928 & 117 & 27.35 & 10 & & SARII_II78 & pstC (-) & SARII_II79 & pstS (-) \\
\hline II236|7-II23934 & 318 & 27.04 & 192 & & SARII_II69 & hyp. protein (-) & SARII_II70 & hyp. protein (-) \\
\hline | |8|972-| |8207| & 100 & 27 & 77 & & SARII_I238 & sfuC (-) & SARII_I239 & hyp. protein (-) \\
\hline 670506-670772 & 267 & 26.97 & 194 & & SARII_0685 & $\operatorname{moe} A(-)$ & SARII_0686 & hyp. protein (-) \\
\hline 1074|89-1074359 & $17 \mid$ & 26.9 & 650 & rpsL motif (-) & SARII_II2I & $r p s L(-)$ & SARII_II22 & $\operatorname{rpoC}(-)$ \\
\hline |64|39-|6426| & 123 & 26.82 & 90 & & SARII_0I60 & COG0647G (-) & SARII_0I6I & $\operatorname{groES}(+)$ \\
\hline $1245732-1245856$ & 125 & 26.4 & 37 & & SARII_I309 & hyp. protein (+) & SARII_I310 & $a m t(+)$ \\
\hline
\end{tabular}


makes identification of the RNA more difficult because the region between the two sections varies in length between 75 and $125 \mathrm{bp} \mathrm{[33],} \mathrm{and} \mathrm{the} \mathrm{permuted} \mathrm{model} \mathrm{is}$ not currently represented in the Rfam database [24].

By applying length, \%GC and conservation thresholds we have significantly enriched our list of IGRs for known structured RNAs. Only, 4\% of all IGRs in 'Cand. P. ubique' contain known structured RNAs. Approximately $17 \%$ of IGRs greater than 100 bp contain structured RNA; and eliminating IGRs with $<26 \%$ GC increases this percentage to $\sim 40 \%$. Applying the BLAST hit threshold further increases percentage of considered IGRs containing known structured RNAs to $75 \%$. However, our parameter choices do exclude 2 of the 34 IGRs $(6 \%)$ containing previously known RNAs. The first is a tRNA that is found within an IGR of $98 \mathrm{bp}$. We explored lowering the $100 \mathrm{bp}$ threshold. However, we identified few additional candidates, and these candidates typically were very close to previously established thresholds for other parameters further decreasing their attractiveness for comprehensive study. The second example of a known RNA we excluded using our parameters is the IGR containing a SAM-II riboswitch preceding met $X$ (SAR11_0217), which failed to rank highly based on GC-enrichment. The IGR containing this riboswitch is 191 nucleotides long and 22.5\% GC (ranked $121^{\text {st }}$ in the genome based on Additional file 1). However, the SAM-II aptamer alone is 70 nucleotides long and 30\% GC. An early investigation of the 'Cand. P. ubique' genome did explore ranking the IGRs by the highest percent GC within a "sliding window" of 50 nucleotides [19]. However, this did not change the rankings of 'Cand. P. ubique' IGRs significantly $\left(\mathrm{R}^{2}=0.84\right.$, Additional file 3$)$. Thus, this additional level of complexity was not implemented for the final analysis.

For those IGRs that are longer than $100 \mathrm{bp}$, greater than $26 \%$ GC, and well-conserved in the marine metagenome (Table 1) but do not contain known structured RNAs, similar sequences identified by the BLAST analysis were used as input for comparative sequence analysis algorithms employed for ncRNA discovery. For each IGR several hypothetical alignments and secondary structures were generated using a covariance model search [34]. These alignments and predicted secondary structures were then used as the starting point for homology searches of the NCBI and metagenomic sequence databases to identify additional examples $[35,36]$. To confirm and refine secondary-structure models and sequence alignments, all examples for a particular IGR were subsequently combined and the process repeated beginning with the covariance model search to generate an RNA secondary structure that is well-supported by a large number of representatives (100-300 unique sequences).
Using this strategy, we discovered candidate structured RNA elements located 5 ' relative to genes encoding ribosomal proteins S2 (rpsB) and S12 (rpsL), and the signal recognition particle protein $(f f h)$. We also found a structured RNA element associated with genes for the methionine biosynthesis proteins $\mathrm{O}$-acetylhomoserine (thiol)-lyase (met $Y$ ), homoserine $S$-methyltransferase ( $\mathrm{mmum}$ ) and betaine-homocysteine methyltransferase (bhmt) (Figure 2). Moreover, we identified a series of IGRs that contain potential RNA structures that are less well-supported by the alignments and often include highly conserved regions with few mutations and thus few opportunities to observe covariation and compatible mutations that are the hallmark of a correctly predicted RNA secondary structure (Figure 3). Features of these new-found candidate structured RNAs are described below.

\section{rpsB motif}

We identified a likely RNA motif preceding the gene $r p s B$, which encodes ribosomal protein S2. The motif is present in both marine metagenomic sequences and most Alphaproteobacteria with the exception of most members of the Rickettsiaceae family (Additional file 4). In addition, we identified representatives in most Gammaproteobacteria, a few Epsilon-, Delta-, and Betaproteobacteria, Cyanobacteria, and some Firmicutes. In nearly all examples where the downstream genes can be determined, the motif precedes $r p s B$. However, a few precede $f t s$, which encodes elongation factor Ts (Ef-Ts) and is often found in the same operon as $r p s B$ [37].

The structure of $r p s B$ motif (Figure 2A) consists of a long base-paired structure (P1) capped by a three-stem junction carrying two variable length stems (P2 and P3), both of which may be very short, or absent in some representatives. The nucleotide junction between P2 and P3 (J2-3) forms a pseudoknot with the 3 ' extension following P1. P2 is quite short in 'Cand. P. ubique' and consists of only three base pairs. In Cyanobacteria, Firmicutes, and most Gammaproteobacteria this pairing element is entirely absent or very short (three or fewer base pairs). In contrast, $\mathrm{P} 2$ is up to eleven base-pairs in some species of Alphaproteobacteria. P3 is also quite short in 'Cand. P. ubique' with only two base pairs, however, it is typically at least four base pairs and has greater than twelve base pairs in several species of Alpha- and Gammaproteobacteria. The pseudoknot interaction is present across all of the taxa. However, in Firmicutes it appears to only consist of three base pairs rather than the five predicted in other phylogenetic groups.

Cis-regulatory elements in the 5 ' untranslated regions (UTRs) of ribosomal protein encoding mRNAs have long been known [38]. Ribosomal proteins L1 [39], L4 [40,41], L10/L12 [42], L20 [43], S4 [44,45], S7 [46], S8 [47,48], 
A $r p s B$ motif

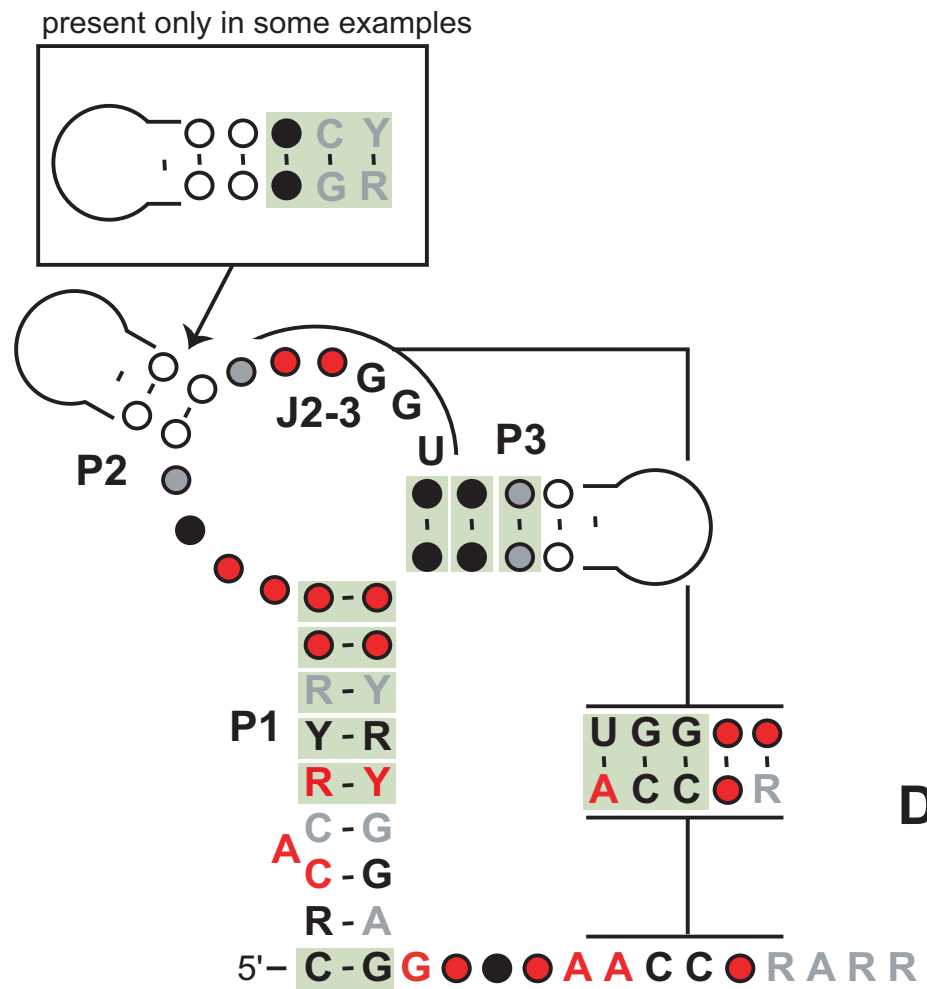

C ffh motif

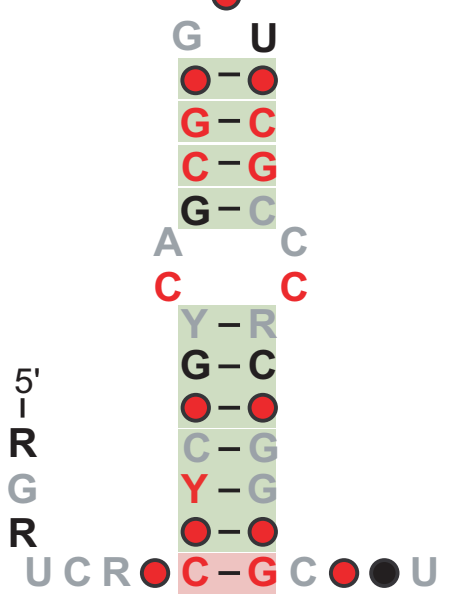

B rpsL motif

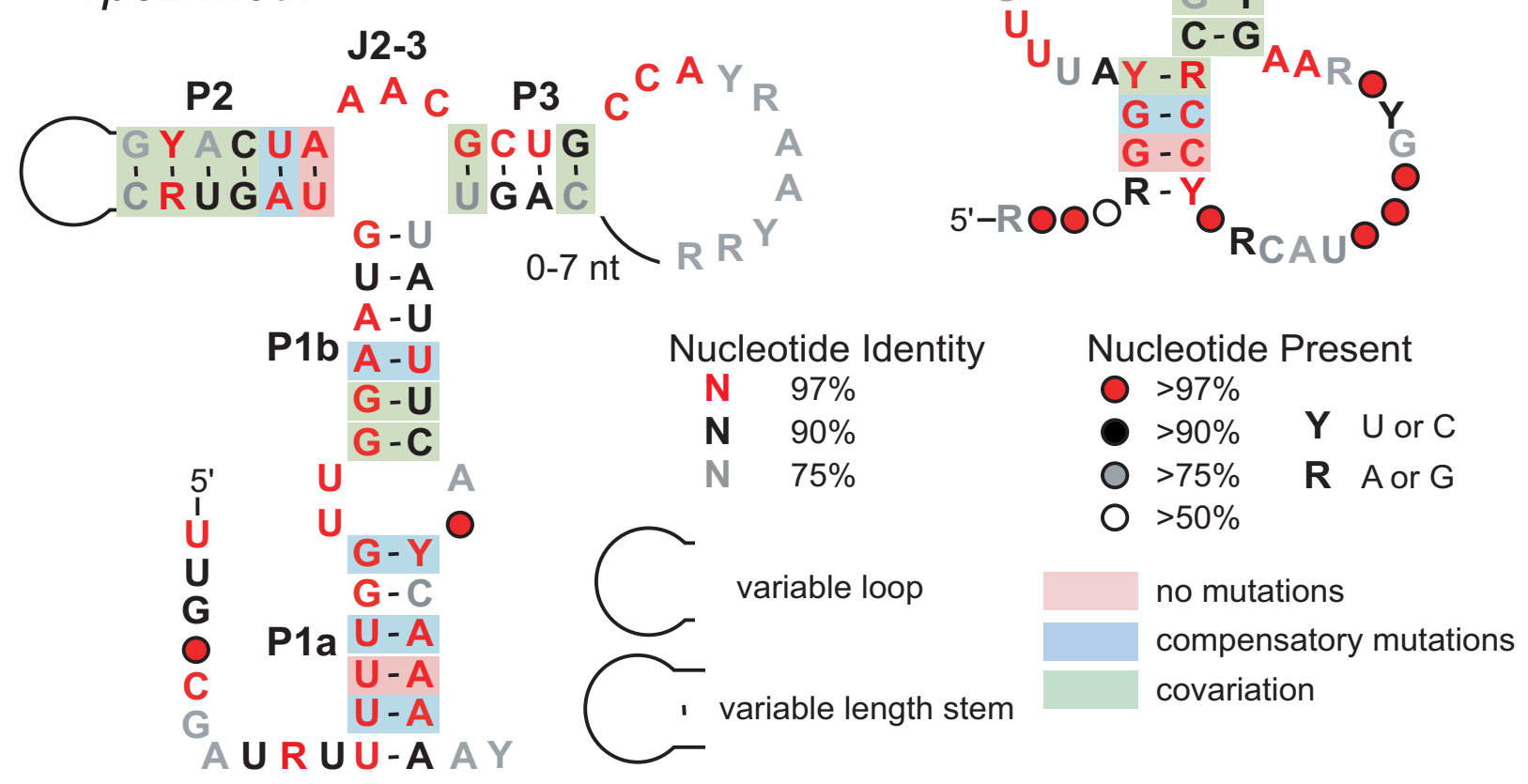

Figure 2

Consensus sequences and structures for the four RNA motifs identified. (A) rpsB motif, (B) $r p s L$ motif, (C) ffh motif, (D) SAM-V riboswitch. See Additional files 4, 5, 6, 7 for alignments of all representatives. Calculations for conservation of nucleotide identity are described in the Methods section. Proposed base pairs with more than $5 \%$ non-canonical Watson-Crick pairings or missing nucleotides are not classified as covarying. 


\section{A rhtB element B pntA element $\quad$ C bablM element}

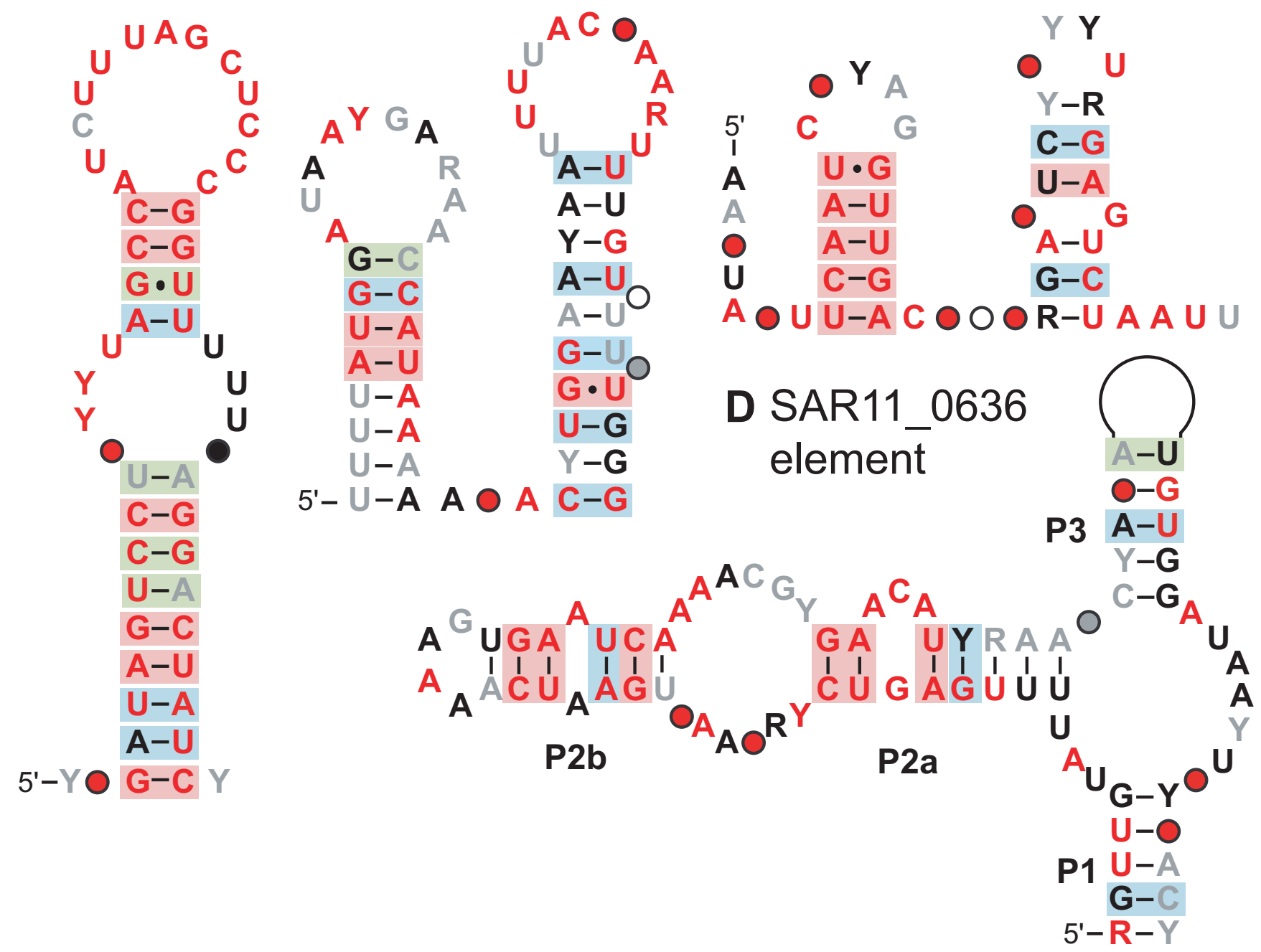

Figure 3

The conserved sequence and secondary structure of the four candidate RNA motifs identified. (A) rht $B$ associated element, (B) pntA associated element, (C) babIM associated element, (D) SARII_0636 element. See Additional files 8, 9, I0, II for alignments of all representatives. Structural notations are as in Fig. 2, and consensus nucleotides and covariation computed identically to Fig. 2.

S15 [49], and S1 [50] are known to bind mRNA sequences to control gene expression. All such sequences characterized to date are autoregulatory, where the mRNA is bound by a ribosomal protein encoded within the transcript [38]. Typically such sequences inhibit translation, although some regulate transcription $[41,51]$.

The role of the S2 ribosomal protein in translation is not well understood. S2 binds the 30S subunit late in ribosome biogenesis and acts as a bridge between the 16S RNA and ribosomal protein $\mathrm{S} 1$, which is the only ribosomal protein contacting the $30 \mathrm{~S}$ subunit through protein-protein interactions [52]. The function of $S 1$ is similarly unclear; however it has been implicated in translating highly structured mRNAs [53], as well as in the formation of the translation initiation complex at internal ribosome binding sites [54]. Analysis of the crystal structure of the 30 S subunit from $T$. Thermophilus ribosome shows that S2 contacts distal regions of the 16S RNA (H26 in the body and H35-37 in the body) [55]. These regions bear no obvious resemblance to the motif we have identified. However, structural mimicry cannot be excluded. In several instances the 5' UTR of an mRNA and the ribosomal RNA bound by the same protein share similar tertiary structures despite having little or no primary or secondary structure similarity [56-59]. 
The region upstream of the ribosomal protein S2 was identified as a potential 5' UTR in a transcriptome analysis of Escherichia coli $[60,61]$. In addition, recent in vivo work in $E$. coli shows that the region 162 nucleotides upstream of $r p s B$ controls an $r p s B$-lacZ fusion construct in response to exogenous $\mathrm{S} 2$ added in trans [62]. This work identified the conserved RNA structure upstream of $r p s B$ in other Gammaproteobacteria. However, we identified a more broadly conserved motif in Alpha- Beta- and Deltaproteobacteria as well as Cyanobacteria and Firmicutes. In addition, the pseudoknot interaction had not previously been identified.

\section{rpsL motif}

A second putative motif in the 5' UTR of a ribosomal mRNA was identified for $r p s L$ (encoding ribosomal protein S12), the first gene in a series of 22 genes encoding ribosomal proteins in 'Cand. P. ubique' that are homologous to those in the E. coli str, spc, and $S 10$ ribosomal operons. We identified over 900 representatives (659 unique sequences) of the motif in the marine metagenome in addition to the instance in 'Cand. P. ubique' (Additional file 5). The motif is consistently identified 3' of $r p o C$, which encodes RNA polymerase, and 5 ' of $r p s L$. The genes further downstream of $r p s L$ are typically those identified in the 'Cand. P. ubique' operon. However, due to the length of the metagenomic sequences analyzed it is impossible to determine whether the entire series of ORFs is conserved. The motif occasionally precedes $r p s G$ or fusA genes that directly follow $r p s L$ in the 'Cand. P. ubique' genome. Despite extensive searching, we only identified the motif in 'Cand. P. ubique' and marine metagenomic sequence samples.

The motif consists of a bulged P1 stem connecting to a three-stem junction (Figure 2B). The P2 stem shows covariation throughout its length, however, the loop region is diverse both in length (3-10 nt) and sequence. Both the $\mathrm{P} 1$ and P3 stems show some covariation, but more positions exhibit breaks in the Watson-Crick base pairing compared with the P2 stem. The nucleotides in J2-3 are identical in nearly all examples, and the P3 loop and P1 bulge also show extensive conservation.

Several proteins encoded by this series of ribosomal protein genes in 'Cand. P. ubique' have been shown to regulate ribosomal protein expression in E. coli $[40,41,46-$ 48,62 . The str ribosomal operon (encoding ribosomal proteins $\mathrm{S} 12, \mathrm{~S} 7$, and elongation factors $\mathrm{G}$ and $\mathrm{Tu}$ ) is regulated by the binding of $S 7$ to the transcript region between the genes for S12 and S7 [46]. Similarly, the spc operon (encoding ribosomal proteins L14, L24, L5, S14, S8, L6, L18, S5, L30 L15 and secY) is regulated by S8 binding to an mRNA structure between L24 and L5 $[47,48]$. The eleven-gene $S 10$ operon (encoding ribosomal pro- teins S10, L3, L4, L23, L2, S19, L22, S3, L16, L29, S17) is regulated by ribosomal protein L4 binding to a 5' UTR preceding the S10 gene $[40,41]$.

The secondary structure of the motif described here does not bear any resemblance to the regulatory motifs associated with S7, S8 and L4. Additionally, the rpsL motif is not located at the same genomic position as any of the E. coli regulatory motifs. While this series of ribosomal proteins in 'Cand. P. ubique' essentially consists of the three separate $E$. coli operons, separate regulation in this organism is unlikely as the coding regions typically overlap by a few base pairs and the largest IGR is nine nucleotides. This motif is not identified outside of 'Cand. P. ubique' and the metagenomic data. However, given its genomic context and conserved secondary structure, the rpsL motif is likely a structured RNA involved with regulation of ribosomal protein expression. Considering the large number of potential candidates, we cannot predict with confidence which protein may be its binding partner.

\section{ffh motif}

We identified an RNA motif in the IGR preceding the gene $f f h$ which encodes the cytoplasmic protein component of the bacterial signal recognition particle (SRP). The motif is well-conserved in metagenomic sequence samples with over 600 representatives (345 unique sequences) (Additional file 6). In addition, this motif is widespread among Alphaproteobacteria occurring in all fully-sequenced representatives of the Rhodobacterales, Sphingomonadales and Rhizobiales classes. However, the ffh motif does not occur in any sequenced representatives of the Rhodospirillales or Caulobacterales classes and it is also not found in representatives of Rickettsiales other than 'Cand. P. ubique'. In nearly all examples where the downstream genes can be identified, the motif precedes ffh. This transcript has been detected by several metatranscriptomics analyses of microbial small RNAs $[63,64]$.

The RNA motif consists of a single bulged hairpin (Figure 2C). However, there is convincing co-variation found at all positions along the stem with the exception of the first base-pair which is always a cytosine-guanosine pair. Additionally, there is significant sequence conservation within the bulge. In particular the two cytosine residues are found in nearly every example.

The signal recognition particle (SRP) is an essential RNAprotein complex conserved in all three domains of life that targets secreted proteins to the plasma membrane in eubacteria and archaea or to the endoplasmic reticulum in eukaryotes through interactions with peptide signal sequences [21]. The eubacterial SRP complex consists of the 4.5S RNA, a cytoplasmic protein (Ffh), and a receptor protein (FstY) that targets the complex to the membrane. 
Ffh binds directly to a conserved portion of the 4.5S RNA known as helix 8 [65], and FstY in turn binds Ffh $[66,67]$. The eukaryotic and archaeal SRPs typically consist of larger RNAs and a greater number of proteins. However, the interactions between the RNA component and the cytoplasmic protein are conserved [68].

How the levels of the Ffh protein and the 4.5S RNA are regulated is not fully understood. In E. coli the 4.5S RNA is present in excess compared to Ffh [69], and it has been shown using both depletion studies [70] and examination of a temperature sensitive ffh mutant in E. coli [71] that Ffh is significantly stabilized by its interactions with the 4.5S RNA and is rapidly degraded when not bound to the RNA. However, no regulation at the transcriptional or translational level has been described. The RNA motif identified does not appear to resemble the portion of the 4.5S RNA bound by Ffh. However, it is possible that the motif plays a role in the regulation of the ffh gene, especially given the widespread distribution of this motif and the precedent for cis-regulatory mRNA elements associated with the genes of RNA binding proteins [72].

\section{Methionine biosynthesis associated motif}

We identified a conserved RNA motif preceding the methionine biosynthesis genes mmum, metY, and bhmt. This conserved sequence was previously identified as a potential regulatory region in 'Cand. P. ubique' as the three genes appear to be co-regulated from proteomic studies [73]. We found 690 representatives (505 unique sequences) in metagenomic sequences, most of which precede metY (Additional file 7). However, there are metagenomic examples that precede bhmt, metH, and mmum. In addition, there is a single example in the genome of Psychroflexus torquis ATCC 700755 (RefSeq accession NZ_AAPR0000000) also preceding metY.

The motif consists of a simple pseudoknotted structure that is typically within ten nucleotides of a start codon (Figure 2D). Both stems show covariation and many loop nucleotides are well-conserved. Based on the association of the motif with methionine biosynthesis genes, the coregulation of the three genes in 'Cand. P. ubique' [73], and the prevalence of $S$-adenosylmethionine (SAM)-binding riboswitches [74], we hypothesized that the RNA was a SAM-binding riboswitch. In vitro biochemical characterization of the RNA has revealed that representatives of this RNA motif selectively bind SAM (M. Meyer, E. Poiata, and R. Breaker; unpublished data).

The RNA motif also displays some similarities to the previously described class II SAM riboswitches (SAM-II) that bind SAM and control sulfur metabolism genes in Alphaproteobacteria [28]. In particular the two RNA motifs share a similar overall pseudoknotted structure and many of the bases shown to contact the ligand in a crystal structure of the class II SAM riboswitch [75] have equivalent nucleotides in the new-found motif. Despite these similarities, the motif lacks the final 3' base-pairing element present in most SAM-II riboswitch representatives. Moreover, both paired regions in the new motif differ in length from those in the SAM-II consensus, and the loop regions outside those that bind the ligand in the SAM-II riboswitch are not well conserved. Such differences in the riboswitch aptamers for SAM-I and SAM-IV riboswitches cause representatives to be sorted into distinct collections when examined using bioinformatics search algorithms that identify common sequence and structural elements [76]. Likewise, the differences between SAM-II and the new-found motif also cause them to be sorted independently, suggesting that this is a new class of SAM-binding riboswitches that we have termed SAM-V.

\section{Other potential RNA motifs}

In addition to the motifs that we identified that have strong support as structured RNAs based on their alignments and distribution, we also identified several potential RNA motifs that are less well-supported. These candidate RNA motifs have fewer positions with covariation or compatible mutations and are not identified outside the genome of 'Cand. P. ubique' and metagenomic sequences. However, they do exhibit evidence of possible RNA structure formation and our models are supported by sequence alignments from the marine metagenome.

The first of these motifs consists of a single bulged hairpin (Figure 3A). Both portions of the stem are conserved, and show indications of covariation and compatible mutations at many positions. Both the loop and the bulge are also well-conserved. The alignment consists of 1250 representatives (919 unique sequences) from the marine metagenome and 'Cand. P. ubique' (Additional file 8). In 'Cand. P. ubique' the motif is flanked by a hypothetical protein and $r h t B$ (LysE type translocator). In the metagenomic sequence, this context is largely conserved. However, the motif also appears upstream of proC (pyrroline-5-carboxylate reductase), as well as other genes further downstream of rhtB in 'Cand. P. ubique' such as livM and livK (components of putative branched amino acid transporters). Approximately $50 \%$ of examples of this motif, including the one in 'Cand. P. ubique', are directly followed by a poly-uridine track of 6-9 nucleotides potentially forming a rho-independent terminator stem [77]. This feature suggests either a potential regulatory function or a conserved termination signal. However, the lower portion of the well-conserved hairpin structure also forms a fairly convincing inverted repeat sequence, which may indicate alternative functionality. 
The second motif consists of two base-paired stems in series where the loop of the second is especially well-conserved (Figure 3B). The alignment includes 365 unique sequences derived from metagenomic sequences ( $\sim 400$ total representatives), in addition to the example in 'Cand. P. ubique' (Additional file 9). In 'Cand. P. ubique' the motif is flanked by rpmJ, which encodes the ribosomal protein L36, and pntA, which encodes the alpha subunit of a pyridine nucleotide transhydrogenase. In the marine metagenome the motif consistently precedes $p n t A$, but the gene annotated directly $5^{\prime}$ of the motif varies. Most frequently it is the 5S rRNA gene, or $r m l B$ (dTDP-D-glucose 4,6-dehydratase, COG1088). The conserved position of this motif $5^{\prime}$ of the pntA gene suggests a regulatory function related to pntA. However, there is an additional 60 bp of sequence between the motif and the start of the gene. While this sequence is somewhat conserved at the nucleotide level, this region does not appear to have any structure supported by compatible or covarying base-pair interactions.

The third motif (Figure 3C) also consists of a set of predicted base-pairing stems in series. The sequence of the first predicted stem is very strongly conserved, with no mutations observed in any of the representatives identified. The second stem shows a few compatible mutations and the position nearest the loop frequently fails to maintain base pairing. The loops and linker regions exhibit almost no conservation. Approximately 540 representatives (314 unique sequences) were identified in the marine metagenome, and the genomic context is well conserved (Additional file 10). The motif occurs between rnhB1 (RNaseHII) and bablM (a site-specific DNA methylase) in the genome of 'Cand. P. ubique' and the vast majority of metagenomic examples fall between genes annotated as $r n h B 1$ and a DNA methylase.

The fourth motif is somewhat more complex than others in this category (Figure 3D). There are $\sim 640$ representatives (338 unique sequences) in the marine metagenome in addition to that in the genome of 'Cand. P. ubique' (Additional file 11). Its three-stem junction carries a well conserved stem (P2) that contains two bulged regions, one of which is highly conserved. Due to this conservation, none of the base pairs are supported by covariation and only a few by compatible mutations. The other two stems (P1 and P3) are only moderately conserved, and the loop of P3 is variable in length containing between 5 and 12 nucleotides with no strong conservation. The motif occurs between two hypothetical proteins. One (SAR11_0635) is annotated as both an SOS-mediated transcriptional repressor and an S24-like peptidase depending on the database, and the other (SAR11_0636) is annotated as a SOUL heme-binding protein. In the metagenomic data, neither of these associations is strictly conserved and the annotated genes on either side vary widely. The genes annotated directly 5 ' to the motif are typically syntenous with those in 'Cand. P. ubique' (i.e. predicted glycoyltransferase, SAR11_0633). The genes annotated directly 3 ' of the motif show even greater variation and do not seem to be syntenous with the 'Cand. P. ubique' genome. Based on these observations, it seems likely that the RNA is not a cis-regulatory element, but rather could be a separately transcribed non-coding RNA.

Microarray studies show that transcripts for all of these genes, although not necessarily any untranslated regions, are present in 'Cand. P. ubique' during both exponential growth and stationary phase cells. Interestingly, comparison of microarray and quantitative proteomic data (unpublished data) for pntA shows a 300\% increase in protein as cells enter stationary phase, starkly contrasting the corresponding $9 \%$ decease in transcript levels. This disparity between transcript and protein expression provides further evidence for post-transcriptional regulation of the gene. Unfortunately, proteomic data are not available for RhtB and BabIM (not included in the AMT-tag library), and SAR11_0636 was never observed in the proteomic dataset, so direct comparisons are not possible for these genes.

\section{Discussion}

In this study we identified structured RNAs that are conserved in both the genome of 'Cand. P. ubique' and the marine metagenomic datasets. A few these RNAs were assigned to previously-known classes, while this is the first description of others. Our work differs from other surveys of ncRNAs in the metagenome [6,7] in that we did not seek to identify additional examples of known motifs, but rather we sought to discover motifs not previously described. We identified three likely cis-regulatory protein binding motifs and a new riboswitch class, and our approach is validated by the confirmed biological function for two of the four motifs ( $r p s B$ motif and SAM-V riboswitch). In addition to these four RNA cis-regulatory elements, we also describe a series of motifs for which there is less evidence of RNA structure. While these RNA motifs are less well-supported by compatible and covarying mutations than the others we present, the structures are credible given the number of representatives identified, the degree of sequence conservation, and the thermodynamics of RNA folding.

There are many additional IGRs in 'Cand. P. ubique' that contain a high percentage GC and seem highly conserved (Table 1), yet have no discernable RNA structure. For some of these IGRs, the large number of BLAST hits is the result of many different short aligned sections of high identity within the IGR (e.g. the IGR between SAR11_0641 and SAR11_0642). By contrast, in the IGRs 
where we identified convincing structured RNAs there is typically a longer region of alignment with mutations distributed throughout. For several other IGRs there are a large number of BLAST hits that align but form no detectable RNA structure (e.g. the IGR between SAR11_0037 and SAR11_0038). These regions may contain RNAs that are not extensively structured (e.g. antisense RNAs that base pair to target RNAs) [78], or perhaps they are conserved protein binding sites that act at the level of DNA.

The parameters we used to identify IGRs for inspection were based on the properties of previously annotated RNAs and were designed to capture most structured RNAs. However, one IGR containing a known structured RNA does not meet our parameters for inspection. The IGR containing a SAM-II riboswitch preceding metX (SAR11_0217) failed to rank highly based on GC-enrichment. The IGR containing this riboswitch is 191 nucleotides long and $22.5 \%$ GC (ranked $121^{\text {st }}$ in the genome based on Additional file 1), significantly below where we arbitrarily stopped examining IGRs due to the decreasing number of convincing BLAST matches (Table 1). However, the SAM-II aptamer alone is 70 nucleotides long and $30 \%$ GC. An early investigation of the 'Cand. P. ubique' genome did explore ranking the IGRs by the highest percent GC within a "sliding window" of 50 nucleotides [19]. However, this did not change the rankings of 'Cand. P. ubique' IGRs significantly $\left(\mathrm{R}^{2}=0.84\right.$, Additional file 11$)$. Thus, this additional level of complexity was not implemented for the final analysis.

In contrast to other computational genomics studies [3], we identified relatively few candidate RNAs. This is likely because there is relatively little to find in 'Cand. P. ubique' compared with organisms that have larger genomes. The genome of 'Cand. P. ubique' is hypothesized to be streamlined to minimize nutrient use $[14,79]$. Even the strong AT bias may reflect adaptation to nitrogen limitation in a nutrient poor environment because GC pairs require an additional nitrogen compared to AT base pairs. A survey examining lengths of the RNase P RNA, SRP RNA, TPP and glycine riboswitches in 'Cand. P. ubique' compared with those in other Alphaproteobacteria showed that RNAs in 'Cand. P. ubique' have tendency toward fewer nucleotides (Additional file 12). On average they are greater than one standard deviation lower than the mean for a given RNA (average Z-value of -1.12). While this result is not statistically significant, the motifs identified here further reflect this tendency. The S2 motif identified in 'Cand. P. ubique' is among the shortest with an exceedingly short P2 stem (3 bp) and no P3 stem. The presence of RNA-based regulatory motifs in 'Cand. P. ubique' indicates that such mechanisms can be an effective use of scarce resources, and the smaller RNAs likely reflect pressure to decrease the number of nucleotides at both the
DNA and RNA level. Interestingly ribosomal RNAs and tRNAs both showed less variation in length among Alphaproteobacteria than other structured RNAs, as well as less or no evidence of reduction in 'Cand. P. ubique' suggesting that it is difficult to alter RNAs with functions critical for survival.

\section{Conclusion}

This study increased the number of candidate structured RNAs in both 'Cand. P. ubique' and the marine metagenome. Several of the RNAs discovered have wide phylogenetic distribution, while others can only be found through examination of metagenomic data. The combination of computational approaches used in this work is relatively simple and in principle might be applied to any organisms with similar properties. This work also underscores how single completed genomes that are carefully annotated are important components in the effort toward annotating and understanding the vast amount metagenomic data available.

\section{Methods \\ Identification of candidate RNA motifs}

Non-protein coding segments of the 'Cand. P. ubique' genome (RefSeq accession number NC_007205.1) were computationally identified based on the RefSeq version 25 gene annotations and their sequences extracted [80]. The size and percent GC values for these regions were established. Individual sequences annotated as harboring a structured ncRNA according to the Rfam database (version 8.1) were identified [24]. Two additional sequences containing tRNAs were identified from the RefSeq annotation of the 'Cand. P. ubique' genome, and the riboswitches were located based on alignments maintained through periodic homology searches [81].

As all known structured RNAs in 'Cand. P. ubique' are present in IGRs longer than 100 bp (Fig. 1), we used 100 bp as the minimum size requirement for the IGRs we examined. The conservation level for each IGR was determined by the number of hits returned with an E-value less than $10^{-5}$ from a nucleotide BLAST analysis of the IGR against the "GOS: All Metagenomic Sequence Reads" database maintained at the CAMERA website [20]. IGRs not well-conserved in metagenomic sequence data (less than 200 blast hits) were removed from consideration. The remaining IGRs were screened for the presence of unannotated protein coding regions first through BLASTX and subsequently TBLASTX searches of the NCBI $\mathrm{nr}$ and $\mathrm{nr} / \mathrm{nt}$ databases http://www.ncbi.nlm.nih.gov/blast/ Blast.cgi and TBLASTN searches of the "All Metagenomic Sequence Reads" CAMERA database. Those sequences containing a conserved protein coding region (Additional File 2) were excluded from further analysis. 
For the remaining IGRs, all blast matches from the conservation analysis were collected and the sequences extended to match the length of the IGR, or to the end of the sequence read (average trimmed sequence read is $822 \mathrm{bp}$ in length [13]). This collection of sequences was then used as input for CMFinder version 0.2 [34] which created multiple sequence alignments with putative conserved secondary structures. These alignments were manually examined for features indicative of a structured RNA such as extent of covariation within predicted stems and conservation in areas outside base-paired regions. For most IGRs, several alternative structures were initially chosen for further analysis due to the high level of conservation in the sequences.

The alignments and hypothetical secondary structures were used to search for additional homologs in the RefSeq25 database [80] along with metagenome sequences from acid mine drainage [82], soil and whale fall [83], human gut [84,85], mouse gut [86], gutless sea worms [87], sludge [88], Global Ocean Survey scaffolds $[12,13]$, other marine sequences [89] and termite hindgut [90].

Homology searches were performed using RAVENNA version $0.2 \mathrm{f}$, essentially as described previously $[35,36,91,92]$. For each IGR, homologs resulting from these searches were used in conjunction with the original sequences as the starting input for a second CMFinder search and the homology search process was iterated to derive a single structure, or in cases of predicted pseudoknot interactions two compatible structures, supported by the alignment.

\section{Analysis of motifs}

The alignments of IGRs where convincing RNA structure could be identified were manually edited by RALEE [93]. We used RNAshapes [94], CMFinder [34] and RAVENNA [36] during these analyses. Additional homology searches were conducted using the RAVENNA '-local' and '-global' command line options with the microbial subset of RefSeq version 25, and the metagenomic sequence databases described above. As the full RefSeq database is $3,717,469,431$ nucleotides and the combined metagenomic databases total 5,529,658,033 nucleotides, several subset databases (Proteobacteria, Alphaproteobacteria, Bacteroidetes, Additional File 2 and Global Ocean Survey Scaffolds) were used to reduce the number of false positive hits. Local searches tended to have greater success identifying homologs of motifs with variable length or optional stems.

For the genome context annotations, protein-coding genes were assembled from the annotations in RefSeq and from "predicted proteins" [5] in Global Ocean Survey sequences or annonatated genes in IMG/M [95]. However, sequences from three metagenome projects $[85,89,90]$ were extracted from GenBank and genes were predicted using the MetaGene program (dated Oct. 12, 2006) with default parameters [96]. Conserved protein domains were detected using the Conserved Domain Database version 2.08 [97].

The extent of covariation and conservation of sequences reflected in consensus diagrams (e.g. Figure 2) was determined as previously described [92]. Sequences were weighted to de-emphasize highly similar homologs using the GSC algorithm [98] implemented by Infernal [35]. Base pairs where both positions in the sequence alignment varied among sequences while maintaining WatsonCrick or G-U wobble base pairing were classified as covarying. Base pairs where a single position varied were classified as compatible mutations. If the frequency of nonWatson-Crick or G-U pairs exceeded 5\%, no covariation or compatible mutation was annotated.

\section{List of abbreviations}

IGR: intergenic region; ncRNA: noncoding RNA; GOS: Global Oceanographic Survey; CAMERA: Community Cyberinfrastructure for Advanced Marine Microbial Ecology Research and Analysis; SRP: signal recognition particle; UTR: untranslated region; SAM: $S$ adenosylmethionine; bp: base pair.

\section{Authors' contributions}

MMM conceived and designed the study, executed bioinformatics searches, analyzed the data, and drafted the manuscript. TDA participated in the design of the study and provided bioinformatics infrastructure. DPS conceived the study, performed proteomics searches, and revised the manuscript. ZW provided bioinformatics infrastructure and reviewed motif analysis. MSS conceived the study and revised the manuscript. SJG conceived the study and revised the manuscript. RRB participated in the design of the study, reviewed motif analysis, and revised the manuscript. All authors read and approved the final manuscript.

\section{Additional material}

\section{Additional file 1}

All 'Cand. P. ubique' IGRs greater than $100 \mathrm{bp}$. A list of all intergenic regions in 'Cand. P. ubique' longer than 100 bp with the length, GC content and annotated RNAs indicated.

Click here for file

[http://www.biomedcentral.com/content/supplementary/14712164-10-268-S1.doc] 


\section{Additional file 2}

Misannotated protein coding regions identified. A list of likely misannotated protein coding regions identified in the course of this study.

Click here for file

[http://www.biomedcentral.com/content/supplementary/1471-

2164-10-268-S2.doc]

\section{Additional file 3}

IGR ranking by \%GC and sliding window \%GC. Comparison of ranking IGRs by \%GC and an alternative ranking methodology based on a sliding window of 50 nucleotides.

Click here for file

[http://www.biomedcentral.com/content/supplementary/14712164-10-268-S3.doc]

\section{Additional file 4}

rpsB alignment. Text file containing Stockholm alignment of the rpsB motif, may be viewed in any text editor including XEmacs with the RALEE extension, or MS-wordpad.

Click here for file

[http://www.biomedcentral.com/content/supplementary/1471-

2164-10-268-S4.txt]

\section{Additional file 5}

rpsL alignment. Text file containing Stockholm alignment of the rpsL motif, may be viewed in any text editor including XEmacs with the RALEE extension, or MS-wordpad.

Click here for file

[http://www.biomedcentral.com/content/supplementary/1471-

2164-10-268-S5.txt]

\section{Additional file 6}

ffh alignment. Text file containing Stockholm alignment of the $\mathrm{ffh}$ motif, may be viewed in any text editor including XEmacs with the RALEE extension, or MS-wordpad.

Click here for file

[http://www.biomedcentral.com/content/supplementary/14712164-10-268-S6.txt]

\section{Additional file 7}

SAMV alignment. Text file containing Stockholm alignment of the SAM$V$ motif, may be viewed in any text editor including XEmacs with the RALEE extension, or MS-wordpad.

Click here for file

[http://www.biomedcentral.com/content/supplementary/14712164-10-268-S7.txt]

\section{Additional file 8}

rhtb alignment. Text file containing Stockholm alignment of the rhtb motif, may be viewed in any text editor including XEmacs with the RALEE extension, or MS-wordpad.

Click here for file

[http://www.biomedcentral.com/content/supplementary/1471-

2164-10-268-S8.txt]

\section{Additional file 9}

pntA alignment. Text file containing Stockholm alignment of the pntA motif, may be viewed in any text editor including XEmacs with the RALEE extension, or MS-wordpad.

Click here for file

[http://www.biomedcentral.com/content/supplementary/14712164-10-268-S9.txt]

\section{Additional file 10}

bablM alignment. Text file containing Stockholm alignment of the bablM motif, may be viewed in any text editor including XEmacs with the RALEE extension, or MS-wordpad.

Click here for file

[http://www.biomedcentral.com/content/supplementary/1471-

2164-10-268-S10.txt]

\section{Additional file 11}

SAR11_0636 alignment. Text file containing Stockholm alignment of the SAR11_0636 motif, may be viewed in any text editor including XEmacs with the RALEE extension, or MS-wordpad.

Click here for file

[http://www.biomedcentral.com/content/supplementary/14712164-10-268-S11.txt]

\section{Additional file 12}

RNA motifs from Alphaproteobacteria ordered by length. Glycine riboswitch, TPP riboswitch, SRP, and RNaseP RNAs from Alphaproteobacteria ordered by length.

Click here for file

[http://www.biomedcentral.com/content/supplementary/14712164-10-268-S12.doc]

\section{Acknowledgements}

We thank Dr. Ming Chen Hammond for helpful discussions, N. Carriero and R. Bjornson for assisting our use of the Yale Life Sciences High Performance Computing Center (NIH grant RR 19895-02), and the Pacific Northwest National Laboratory for the quantitative proteomic analysis. The work reported here was supported in part by NIH award U54AI57I 58 (Northeast Biodefense Center - Lipkin). M.M.M. is supported by an NIH NRSA (F32GM079974) and the Breaker Lab also receives support from the Howard Hughes Medical Institute. Portions of this work were also supported by a Marine Microbiology Initiative investigator award from the Gordon and Betty Moore Foundation.

\section{References}

I. Huttenhofer A, Vogel J: Experimental approaches to identify non-coding RNAs. Nucleic Acids Res 2006, 34:635-646.

2. Altuvia S: Identification of bacterial small non-coding RNAs: experimental approaches. Curr Opin Microbiol 2007, 10:257-26I.

3. Eddy SR: Computational genomics of noncoding RNA genes. Cell 2002, 109:137-140.

4. Jossinet F, Ludwig TE, Westhof E: RNA structure: bioinformatic analysis. Curr Opin Microbiol 2007, 10:279-285.

5. Yooseph S, Sutton G, Rusch DB, Halpern AL, Williamson SJ, Remington K, Eisen JA, Heidelberg KB, Manning G, Li W, Jaroszewski L, Cieplak P, Miller CS, Li H, Mashiyama ST, Joachimiak MP, van Belle C, Chandonia JM, Soergel DA, Zhai Y, Natarajan K, Lee S, Raphael BJ, Bafna V, Friedman R, Brenner SE, Godzik A, Eisenberg D, Dixon JE, Taylor SS, Strausberg RL, Frazier M, Venter JC: The Sorcerer II Global Ocean Sampling expedition: expanding the universe of protein families. PLoS Biol 2007, 5:el6.

6. Kazanov MD, Vitreschak AG, Gelfand MS: Abundance and functional diversity of riboswitches in microbial communities. BMC Genomics 2007, 8:347.

7. Zhu Y, Pulukkunat DK, Li Y: Deciphering RNA structural diversity and systematic phylogeny from microbial metagenomes. Nucleic Acids Res 2007, 35:2283-2294.

8. Mavromatis K, Ivanova N, Barry K, Shapiro H, Goltsman E, McHardy AC, Rigoutsos I, Salamov A, Korzeniewski F, Land M, Lapidus A, Grigoriev I, Richardson P, Hugenholtz P, Kyrpides NC: Use of simulated data sets to evaluate the fidelity of metagenomic processing methods. Nat Methods 2007, 4:495-500. 
9. Raes J, Foerstner KU, Bork P: Get the most out of your metagenome: computational analysis of environmental sequence data. Curr Opin Microbiol 2007, 10:490-498.

10. Yooseph S, Li W, Sutton G: Gene identification and protein classification in microbial metagenomic sequence data via incremental clustering. BMC Bioinformatics 2008, 9:182.

II. Morris RM, Rappe MS, Connon SA, Vergin KL, Siebold WA, Carlson CA, Giovannoni SJ: SARI I clade dominates ocean surface bacterioplankton communities. Nature 2002, 420:806-810

12. Venter JC, Remington K, Heidelberg JF, Halpern AL, Rusch D, Eisen JA, Wu D, Paulsen I, Nelson KE, Nelson W, Fouts DE, Hoffman J, Parsons R, Baden-Tillson H, Pfannkoch C, Rogers YH, Smith HO: Environmental genome shotgun sequencing of the Sargasso Sea. Science 2004, 304:66-74

13. Rusch $D B$, Halpern AL, Sutton $G$, Heidelberg $K B$, Williamson $S$, Yooseph S, Wu D, Eisen JA, Hoffman JM, Remington K, Beeson K, Tran B, Smith H, Baden-Tillson H, Stewart C, Thorpe J, Freeman J, Andres-Pfannkoch C, Venter JE, Li K, Kravitz S, heidelberg JF, Utterback T, Rogers YH, Falcón LI, Souza V, Bonilla-Rosso G, Equiarte LE, Karl DM, Sathyendranath S, Platt T, Bermingham E, Gallardo V, Tamayo-Castillo G, Ferrari MR, Strausberg RL, Nealson K, Friedman R, Frazier M, Venter JC: The Sorcerer II Global Ocean Sampling expedition: northwest Atlantic through eastern tropical Pacific. PLoS Biol 2007, 5:e77.

14. Giovannoni SJ, Tripp HJ, Givan S, Podar M, Vergin KL, Baptista D, Bibbs L, Eads J, Richardson TH, Noordewier M, Rappé MS, Short JM, Carrington JC, Mathur EJ: Genome streamlining in a cosmopolitan oceanic bacterium. Science 2005, 309: /242-। 245.

15. Rivas E, Klein RJ, Jones TA, Eddy SR: Computational identification of noncoding RNAs in E. coli by comparative genomics. Curr Biol 200I, I I: I369-I373.

16. Klein RJ, Misulovin Z, Eddy SR: Noncoding RNA genes identified in AT-rich hyperthermophiles. Proc Natl Acad Sci USA 2002, 99:7542-7547.

17. Larsson P, Hinas A, Ardell DH, Kirsebom LA, Virtanen A, Soderbom F: De novo search for non-coding RNA genes in the AT-rich genome of Dictyostelium discoideum: performance of Markov-dependent genome feature scoring. Genome Res 2008, 18:888-899.

18. Schattner P: Searching for RNA genes using base-composition statistics. Nucleic Acids Res 2002, 30:2076-2082.

19. Upadhyay R, Bawankar P, Malhotra D, Patankar S: A screen for conserved sequences with biased base composition identifies noncoding RNAs in the A-T rich genome of Plasmodium falciparum. Mol Biochem Parasitol 2005, 144:149-158.

20. Seshadri R, Kravitz SA, Smarr L, Gilna P, Frazier M: CAMERA: community resource for metagenomics. PLOS Biol 2007, 5:e75.

2I. Pool MR: Signal recognition particles in chloroplasts, bacteria, yeast and mammals. Mol Membr Biol 2005, 22:3-15.

22. Altman S: A view of RNase P. Mol Biosyst 2007, 3:604-607.

23. Kazantsev AV, Pace NR: Bacterial RNase P: a new view of an ancient enzyme. Nat Rev Microbiol 2006, 4:729-740.

24. Griffiths-Jones S, Moxon S, Marshall M, Khanna A, Eddy SR, Bateman A: Rfam: annotating non-coding RNAs in complete genomes. Nucleic Acids Res 2005, 33:D I21-124.

25. Winkler WC, Breaker RR: Regulation of bacterial gene expression by riboswitches. Annu Rev Microbiol 2005, 59:487-5I7.

26. Mandal M, Lee M, Barrick JE, Weinberg Z, Emilsson GM, Ruzzo WL, Breaker RR: A glycine-dependent riboswitch that uses cooperative binding to control gene expression. Science 2004, 306:275-279.

27. Tripp HJ, Schwalbach MS, Meyer MM, Kitner JB, Breaker RR, Giovannoni SJ: Unique glycine-activated riboswitch linked to glycineserine auxotrophy in SARI I. Env Microbiol 2009, I I (I):230-238.

28. Corbino KA, Barrick JE, Lim J, Welz R, Tucker BJ, Puskarz I, Mandal $M$, Rudnick ND, Breaker RR: Evidence for a second class of $S$ adenosylmethionine riboswitches and other regulatory RNA motifs in alpha-proteobacteria. Genome Biol 2005, 6:R70.

29. Rodionov DA, Vitreschak AG, Mironov AA, Gelfand MS: Comparative genomics of thiamin biosynthesis in procaryotes. New genes and regulatory mechanisms. If Biol Chem 2002, 277:48949-48959.

30. Winkler W, Nahvi A, Breaker RR: Thiamine derivatives bind messenger RNAs directly to regulate bacterial gene expression. Nature 2002, 419:952-956.
31. Moore SD, Sauer RT: The tmRNA system for translational surveillance and ribosome rescue. Annu Rev Biochem 2007, 76:10I-124.

32. Keiler KC, Shapiro L, Williams KP: tmRNAs that encode proteolysis-inducing tags are found in all known bacterial genomes: A two-piece tmRNA functions in Caulobacter. Proc Natl Acad Sci USA 2000, 97:7778-7783.

33. Zwieb C, Gorodkin J, Knudsen B, Burks J, Wower J: tmRDB (tmRNA database). Nucleic Acids Res 2003, 3 I:446-447.

34. Yao Z, Weinberg Z, Ruzzo WL: CMfinder-a covariance model based RNA motif finding algorithm. Bioinformatics 2006, 22:445-452.

35. Eddy SR: Infernal Users Guide. 2009 [ftp://selab.janelia.org/pub/ software/infernal/Userguide.pdf]

36. Weinberg Z, Ruzzo WL: Sequence-based heuristics for faster annotation of non-coding RNA families. Bioinformatics 2006, 22:35-39.

37. An G, Bendiak DS, Mamelak LA, Friesen JD: Organization and nucleotide sequence of a new ribosomal operon in Escherichia coli containing the genes for ribosomal protein S2 and elongation factor Ts. Nucleic Acids Res 198I, 9:4163-4I72.

38. Zengel JM, Lindahl L: Diverse mechanisms for regulating ribosomal protein synthesis in Escherichia coli. Prog Nucleic Acid Res Mol Biol 1994, 47:33I-370.

39. Gourse RL, Sharrock RA, Nomura M: Control of ribosome synthesis in Escherichia coli. In Structure, function and genetics of ribosomes Edited by: Hardesty B, Kramer G. New York: Springer; 1986:766-788.

40. Yates JL, Nomura M: E. coli ribosomal protein L4 is a feedback regulatory protein. Cell 1980, 21:517-522.

41. Zengel JM, MueckI D, LindahI L: Protein L4 of the E. coli ribosome regulates an eleven gene $r$ protein operon. Cell 1980, $21: 523-535$

42. Johnsen M, Christensen T, Dennis PP, Fiil NP: Autogenous control: ribosomal protein LIO-LI2 complex binds to the leader sequence of its mRNA. Embo J 1982, I:999-1004.

43. Guillier M, Allemand F, Raibaud S, Dardel F, Springer M, Chiaruttin $C$ : Translational feedback regulation of the gene for $L 35$ in Escherichia coli requires binding of ribosomal protein L20 to two sites in its leader mRNA: a possible case of ribosomal RNA-messenger RNA molecular mimicry. RNA 2002, 8:878-889.

44. Jinks-Robertson S, Nomura M: Ribosomal protein S4 acts in trans as a translational repressor to regulate expression of the alpha operon in Escherichia coli. I Bacteriol 1982, I5I:193-202.

45. Grundy F], Henkin TM: The rpsD gene, encoding ribosomal protein S4, is autogenously regulated in Bacillus subtilis. J Bacteriol 1991, 173:4595-4602.

46. Saito K, Mattheakis LC, Nomura M: Post-transcriptional regulation of the str operon in Escherichia coli. Ribosomal protein S7 inhibits coupled translation of S7 but not its independent translation. I Mol Biol 1994, 235: I I - I24.

47. Cerretti DP, Mattheakis LC, Kearney KR, Vu L, Nomura M: Translational regulation of the spc operon in Escherichia coli. Identification and structural analysis of the target site for S8 repressor protein. J Mol Biol 1988, 204:309-329.

48. Gregory RJ, Cahill PB, Thurlow DL, Zimmermann RA: Interaction of Escherichia coli ribosomal protein S8 with its binding sites in ribosomal RNA and messenger RNA. J Mol Biol 1988, 204:295-307.

49. Philippe C, Portier C, Mougel M, Grunberg-Manago M, Ebel JP, Ehresmann B, Ehresmann C: Target site of Escherichia coli ribosomal protein SI 5 on its messenger RNA. Conformation and interaction with the protein. J Mol Biol 1990, 2 I I:415-426.

50. Tchufistova LS, Komarova AV, Boni IV: A key role for the mRNA leader structure in translational control of ribosomal protein SI synthesis in gamma-proteobacteria. Nucleic Acids Res 2003, 31:6996-7002.

5I. Lindahl L, Archer R, Zengel JM: Transcription of the SIO ribosomal protein operon is regulated by an attenuator in the leader. Cell 1983, 33:24I-248.

52. Kaczanowska M, Ryden-Aulin M: Ribosome biogenesis and the translation process in Escherichia coli. Microbiol Mol Biol Rev 2007, $71: 477-494$ 
53. Szer W, Hermoso JM, Leffler S: Ribosomal protein SI and polypeptide chain initiation in bacteria. Proc Natl Acad Sci USA 1975, 72:2325-2329.

54. Tedin K, Moll I, Grill S, Resch A, Graschopf A, Gualerzi CO, Blasi U: Translation initiation factor 3 antagonizes authentic start codon selection on leaderless mRNAs. Mol Microbiol 1999, 3 I:67-77.

55. Brodersen DE, Clemons WM Jr, Carter AP, Wimberly BT, Ramakrishnan V: Crystal structure of the $30 \mathrm{~S}$ ribosomal subunit from Thermus thermophilus: structure of the proteins and their interactions with I 6 S RNA. J Mol Biol 2002, 3 I 6:725-768.

56. Merianos $\mathrm{HJ}$, Wang J, Moore PB: The structure of a ribosomal protein S8/spc operon mRNA complex. RNA 2004, 1 0:954-964.

57. Nevskaya N, Tishchenko S, Gabdoulkhakov A, Nikonova E, Nikonov O, Nikulin A, Platonova O, Garber M, Nikonov S, PiendI W: Ribosomal protein LI recognizes the same specific structural motif in its target sites on the autoregulatory mRNA and 23S rRNA. Nucleic Acids Res 2005, 33:478-485.

58. Scott LG, Williamson JR: Interaction of the Bacillus stearothermophilus ribosomal protein SI 5 with its 5'-translational operator mRNA. J Mol Biol 200 I, 3 I 4:4I 3-422.

59. Stelzl U, Zengel JM, Tovbina M, Walker M, Nierhaus $\mathrm{KH}$, Lindahl L, Patel DJ: RNA-structural mimicry in Escherichia coli ribosomal protein L4-dependent regulation of the SIO operon. J Biol Chem 2003, 278:28237-28245.

60. Hershberg R, Altuvia S, Margalit H: A survey of small RNA-encoding genes in Escherichia coli. Nucleic Acids Res 2003, 3 I : I8I 3- 1820.

61. Tjaden B, Saxena RM, Stolyar S, Haynor DR, Kolker E, Rosenow C: Transcriptome analysis of Escherichia coli using high-density oligonucleotide probe arrays. Nucleic Acids Res 2002, 30:3732-3738

62. Aseev LV, Levandovskaya AA, Tchufistova LS, Scaptsova NV, Boni IV: A new regulatory circuit in ribosomal protein operons: S2 mediated control of the rpsB-tsf expression in vivo. RNA 2008, I4: |882-1894

63. Frias-Lopez J, Shi Y, Tyson GW, Coleman ML, Schuster SC, Chisholm SW, Delong EF: Microbial community gene expression in ocean surface waters. Proc Nat Acad Sci USA 2008, I 05:3805-38I 0.

64. Shi Y, Tyson GW, Delong EF: Metatranscriptomics reveals unique microbial small RNAs in the ocean's water column. Nature 2009, 459:266-269.

65. Batey RT, Rambo RP, Lucast L, Rha B, Doudna JA: Crystal structure of the ribonucleoprotein core of the signal recognition particle. Science 2000, 287: I232-1239.

66. Egea PF, Shan SO, Napetschnig J, Savage DF, Walter P, Stroud RM Substrate twinning activates the signal recognition particle and its receptor. Nature 2004, 427:215-22I.

67. Focia PJ, Shepotinovskaya IV, Seidler JA, Freymann DM: Heterodimeric GTPase core of the SRP targeting complex. Science 2004, 303:373-377.

68. Doudna JA, Batey RT: Structural insights into the signal recognition particle. Annu Rev Biochem 2004, 73:539-557.

69. Jensen CG, Pedersen S: Concentrations of 4.5S RNA and Ffh protein in Escherichia coli: the stability of $F \mathrm{fh}$ protein is dependent on the concentration of 4.5S RNA. J Bacteriol 1994, I 76:7|48-7| 54

70. Jensen CG, Brown S, Pedersen S: Effect of 4.5S RNA depletion on Escherichia coli protein synthesis and secretion. J Bacteriol I 994, I 76:2502-2506.

7I. Park SK, Jiang F, Dalbey RE, Phillips GJ: Functional analysis of the signal recognition particle in Escherichia coli by characterization of a temperature-sensitive ffh mutant. J Bacteriol 2002 , | 84:2642-2653.

72. Batey RT: Structures of regulatory elements in mRNAs. Curr Opin Struct Biol 2006, 16:299-306.

73. Sowell SM, Norbeck AD, Lipton MS, Nicora CD, Callister SJ, Smith RD, Barofsky DF, Giovannoni S]: Proteomic analysis of stationary phase in the marine bacterium 'Candidatus Pelagibacter ubique'. Appl Environ Microbiol 2008, 74:4091-4100.

74. Wang JX, Breaker RR: Riboswitches that sense S-adenosylmethionine and S-adenosylhomocysteine. Biochem Cell Biol 2008, 86: $157-168$

75. Gilbert SD, Rambo RP, Van Tyne D, Batey RT: Structure of the SAM-II riboswitch bound to $S$-adenosylmethionine. Nat Struct Mol Biol 2008, I 5: 177-182.
76. Weinberg Z, Regulski EE, Hammond MC, Barrick JE, Yao Z, Ruzzo WL, Breaker RR: The aptamer core of SAM-IV riboswitches mimics the ligand-binding site of SAM-I riboswitches. RNA 2008, I 4:822-828.

77. Henkin TM, Yanofsky C: Regulation by transcription attenuation in bacteria: how RNA provides instructions for transcription termination/antitermination decisions. Bioessays 2002, 24:700-707.

78. Aiba $\mathrm{H}$ : Mechanism of RNA silencing by Hfq-binding small RNAs. Curr Opin Microbiol 2007, 10:134-139.

79. Dufresne A, Garczarek L, Partensky F: Accelerated evolution associated with genome reduction in a free-living prokaryote. Genome Biol 2005, 6:RI4.

80. Pruitt KD, Tatusova T, Maglott DR: NCBI reference sequences (RefSeq): a curated non-redundant sequence database of genomes, transcripts and proteins. Nucleic Acids Res 2007, 35:D61-65.

8I. Barrick JE, Breaker RR: The distributions, mechanisms, and structures of metabolite-binding riboswitches. Genome Biol 2007, 8:R239.

82. Tyson GW, Chapman J, Hugenholtz P, Allen EE, Ram RJ, Richardson PM, Solovyev VV, Rubin EM, Rokhsar DS, Banfield JF: Community structure and metabolism through reconstruction of microbial genomes from the environment. Nature 2004, 428:37-43.

83. Tringe SG, von Mering C, Kobayashi A, Salamov AA, Chen K, Chang HW, Podar M, Short JM, Mathur EJ, Detter JC, et al.: Comparative metagenomics of microbial communities. Science 2005, 308:554-557

84. Gill SR, Pop M, Deboy RT, Eckburg PB, Turnbaugh PJ, Samuel BS, Gordon JI, Relman DA, Fraser-Liggett CM, Nelson KE: Metagenomic analysis of the human distal gut microbiome. Science 2006, 312:1355-1359.

85. Kurokawa K, Itoh T, Kuwahara T, Oshima K, Toh H, Toyoda A, Takami H, Morita H, Sharma VK, Srivastava TP, et al.: Comparative metagenomics revealed commonly enriched gene sets in human gut microbiomes. DNA Res 2007, I4: 169-I8I.

86. Turnbaugh PJ, Ley RE, Mahowald MA, Magrini V, Mardis ER, Gordon JI: An obesity-associated gut microbiome with increased capacity for energy harvest. Nature 2006, 444: |027-I03I.

87. Woyke T, Teeling H, Ivanova NN, Huntemann M, Richter M, Gloeckner FO, Boffelli D, Anderson IJ, Barry KW, Shapiro HJ, Szeto E, Kyrpides NC, Mussmann M, Amann R, Bergin C, Ruehland C, Rubin EM, Dubilier N: Symbiosis insights through metagenomic analysis of a microbial consortium. Nature 2006, 443:950-955.

88. García Martín H, Ivanova N, Kunin V, Warnecke F, Barry KW McHardy AC, Yeates C, He S, Salamov AA, Szeto E, Dalin E, Putman NH, Shapiro HJ, Pangilinan JL, Rigoutsos I, Kyrpides NC, Blackall LL, McMahon KD, Hugenholtz P: Metagenomic analysis of two enhanced biological phosphorus removal (EBPR) sludge communities. Nat Biotechnol 2006, 24: I263-I269.

89. DeLong EF, Preston CM, Mincer T, Rich V, Hallam SJ, Frigaard NU, Martinez A, Sullivan MB, Edwards R, Brito BR, Chisholm SW, Karl DM: Community genomics among stratified microbial assemblages in the ocean's interior. Science 2006, 3 I I:496-503.

90. Warnecke F, Luginbuhl P, Ivanova N, Ghassemian M, Richardson TH, Stege IT, Cayouette M, McHardy AC, Djordjevic G, Aboushadi N, Sorek R, Tringe SG, Podar M, García Martín H, Kunin V, Dalevi D, Madejska J, Kirton E, Platt D, Szeto E, Salamov A, Barry K, Mikhailova B, Kyrpides NC, Matson EG, Ottesen EA, Zhang Z, Hernández M, Murillo C, Acosta LG, Rigoutsos I, Tamayo G, Green BD, Chang C, Rubin EM, Mathur EJ, Robertson DE, Hugenholtz P, Leadbetter JR: Metagenomic and functional analysis of hindgut microbiota of a wood-feeding higher termite. Nature 2007, 450:560-565.

91. Klein RJ, Eddy SR: RSEARCH: finding homologs of single structured RNA sequences. BMC Bioinformatics 2003, 4:44.

92. Weinberg Z, Barrick JE, Yao Z, Roth A, Kim JN, Gore J, Wang JX, Lee ER, Block KF, Sudarsan N, Neph S, Tompa M, Ruzzzo WL, Breaker RR: Identification of 22 candidate structured RNAs in bacteria using the CMfinder comparative genomics pipeline. Nucleic Acids Res 2007, 35:4809-48I9.

93. Griffiths-Jones S: RALEE-RNA ALignment editor in Emacs. Bioinformatics 2005, 2 I:257-259.

94. Steffen P, Voss B, Rehmsmeier M, Reeder J, Giegerich R: RNAshapes: an integrated RNA analysis package based on abstract shapes. Bioinformatics 2006, 22:500-503. 
95. Markowitz VM, Ivanova NN, Szeto E, Palaniappan K, Chu K, Dalevi D, Chen IM, Grechkin Y, Dubchak I, Anderson I, Lykidis A, Mavromatis K, Hugenholtz P, Kyrpides NC: IMG/M: a data management and analysis system for metagenomes. Nucleic Acids Res 2008, 36:D534-538.

96. Noguchi H, Park J, Takagi T: MetaGene: prokaryotic gene finding from environmental genome shotgun sequences. Nucleic Acids Res 2006, 34:5623-5630.

97. Marchler-Bauer A, Anderson JB, Cherukuri PF, DeWeese-Scott C, Geer LY, Gwadz M, He S, Hurwitz DI, Jackson JD, Ke Z, et al.: CDD: a Conserved Domain Database for protein classification. Nucleic Acids Res 2005, 33:DI92-196.

98. Gerstein M, Sonnhammer EL, Chothia C: Volume changes in protein evolution. J Mol Biol 1994, 236: I067-1078.

Publish with Bio Med Central and every scientist can read your work free of charge

"BioMed Central will be the most significant development for disseminating the results of biomedical research in our lifetime. "

Sir Paul Nurse, Cancer Research UK

Your research papers will be:

- available free of charge to the entire biomedical community

- peer reviewed and published immediately upon acceptance

- cited in PubMed and archived on PubMed Central

- yours - you keep the copyright

Submit your manuscript here:

http://www.biomedcentral.com/info/publishing_adv.asp
BioMedcentral 